\title{
Accreditation Process and Outcomes: Experience of the University of Tripoli Alahlia, Libya
}

\author{
Ahmed E. Atia \\ University of Tripoli, Faculty of Medical Technology, Tripoli, LIBYA \\ Department of Anesthesia and Intensive Care \\ Salem A. Elfard \\ University of Zawiya, Faculty of Sciences, Zawiya, LIBYA \\ Department of Computer Sciences \\ National Center for Quality Assurance and Accreditation, Tripoli, LIBYA
}

Tarik F. Idbeaa

Gharyan University, Faculty of Sciences, LIBYA

Department of Computer Sciences

Sheren E. Enjim

University of Tripoli Alahlai, Janzur, LIBYA

Department of Administration Management

Received: 19 April 2020 • Accepted: 31 May 2020 • Published Online: 12 June 2020

\section{Abstract}

Background and objectives: Quality assurance and institutional accreditation in education is becoming of paramount importance. This study aims to assess the impacts of the accreditation process of the National Center for Quality Assurance and Accreditation (NCAAA) on the quality of education in one of private university in Libya. Methods: The research adopts a descriptive study design in University of Tripoli Alahlia (UTA) where an official accreditation process was completed by the NCQAA during 2017-2019. Data were collected using the self-study report that produced by the NCQAA accreditation committee during the accreditation process, and were retrieved in specific data collection sheet by one of the authors. Results: The NCQAA accreditation process that lasted about 4 years brought significant changes in the educational progressions and made the staff members more aware of quality issues in education. Our findings also reported significant improvements in the quality of education in the university. Conclusions: The process of NCQAA accreditation conducted in UTA has been positively improved the quality of education. Data from other institutions would also expressively increase the relevance and rationality of the study.

Keywords: accreditation, educational institution, NCQAA, Libya.

(C) Authors. Terms and conditions of Creative Commons Attribution 4.0 International (CC BY 4.0) apply. Correspondence: Ahmed E. Atia, University of Tripoli, Faculty of Medical Technology, Department of Anesthesia and Intensive Care, Tripoli, LIBYA. E-mail: ah.atia@uot.edu.ly. 
A. E. Atia et al. - Accreditation Process and Outcomes: Experience of the University of Tripoli...

\section{Introduction}

During the last two decades, a tremendous improvement in the field of higher education has been observed, whereby higher education has been moved from an elite organization to a mass contributing sector (Atia \& Elfard, 2020). Progressively, many students are seeking higher education which is often linked with better careers and sophisticated employment chances. For various individuals, university education is the only means for socially and essentially enhancement of their life standards (Ibrahim, 2004).

Educational institutions, mainly private colleges and universities, play a crucial part in country developing by attaining universal competitive benefits. As such, they are likely to yield graduates who hold the essential knowledge and skills required in the international industries and markets (Kashisaz \& Mobarak, 2018). The mission is too remarkable that educational institutions have to frequently and repetitively audit themselves against international standards and stay themselves up-to-date of innovative advances. Thus, there is an urgent necessity to further boost the quality of education (UNESCO, 2007).

The private educational institute is considered as a key partner for the governmental institute in driving the cycle of educational enhancement in most of the Arabic nations. Globally, the private colleges and universities have elaborated in an extensive investment by the higher education sector (Hiyam, 2016). The growth of the higher education in Libya was chiefly controlled by the government, but there was an overt involvement of the private part which denoted in the launching of universities and colleges that honor degrees of higher education in different specialties (Tamtam, 2011). The quality of education offered by most of these private institutions might have played a distinguish role in enhancing and improving the higher education output in the manner of specialties and skills of the graduates (Atia \& Elfard, 2020).

Not until 2006, the higher education institutes in Libya, including private colleges and universities, required no national accreditation. However, due to the rapid progression of education that demanded the construction of a governmental agency with the mission of auditing the quality assurance of higher education. Consequently, the ministry of higher education approved the establishment of National Center for Quality Assurance and Accreditation (NCQAA). Thus, it is now obligatory for all higher education institutes to get accredited by the NCQAA (NCQAA, 2020).

The NCQAA is a self-regulating center with concern under the law by the resolution number 18, 2010 for quality accreditation and assurance in all field of education, at both undergraduate and postgraduate levels. The NCQAA has adapted an inclusive quality assurance and accreditation system issued in the year of 2016 that has derived from international experience with the respect of local characteristics (NCQAA, 2020). Its mission includes implementing standards, measures and procedures for accreditation, revising and assessing performance of current and new institutions, accrediting educational institutions, and supporting quality assurance.

Accreditation in Libyan education sector is the process of evaluating an educational institution and officially recognizes it as having met, or failed the NCQAA criteria. There are two basic types of educational institution accreditation; institutional (nine criteria) and academic program (eight criteria). It involves a site visit for at least three days in each accreditation type by the accreditation committee which apply a critical auditing, with the decision of awarding accreditation to those institutions that meet their criteria.

The study, therefore, aimed to examine the impact of NCQAA accreditation on the quality of education of the University of Tripoli Alahlia (UTA), a private university that has awarded the national accreditation (institutional and academic) by NCQAA accreditation process conducted during 2017-2019. 


\section{Methods}

The study is a descriptive research design conducted in University of Tripoli Alahlia (UTA) where an official accreditation process was completed by the NCQAA during 2017-2019. Ethical approval was obtained from the UTA's research ethics committee. All data obtained were kept strictly confidential and hasn't been exposed to anybody at any stage of the study.

A standardized instrument has been used based on data collected from the self-study report that produced by the NCQAA accreditation committee during the accreditation process, and were retrieved in specific data collection sheet by one of the authors. The collected data involved; mission \& vision, program specification, courses specification, course evaluation survey, student experience survey, program evaluation by graduates, graduate evaluation by stakeholders, course report, annual program report, program evaluation, student representation in committees, academic supervision, declaration of office hours, introduction of learning resources center, structured department development activities, independent evaluation, comparison of student's achievement in different courses, and follow up of student progression.

The collected information was entered into excel spreadsheets and analyzed using IBM SPSS Statistics for Windows, Version 22.0. Armonk, NY: IBM Corp. Chi-square test was used to compare the collected data. $P$-value less than 0.05 was considered statistically significant. A brief summary of all the results was arranged and discussed with the quality control committee of the studied university before drawing our discussion and conclusions for this study. Chi square will be used for testing the significance of data.

\section{Results and discussion}

This study investigated the impact of NCQAA accreditation on the quality of education of the University of Tripoli Alahlia. The obtained results clearly revealed improvement in the quality of education throughout and after NCQAA accreditation compared to the situation before accreditation process. It is obvious that these processes made the staff members more aware of quality issues in education. Although it is hard to provide information on all aspect of the implication of NCQAA accreditation, we have assessed some important points of the impacts before, throughout and after the accreditation exercise in all accredited university departments.

To test the impact of the NCQAA accreditation process on the quality of education at UTA, the following figure and table are used. During the accreditation, programs are assessed and reported regularly with statistics providing the level to which learning outcomes were being attained. Data presented in figure 1 shows improvement in quality of education through and after NCQAA accreditation. Our study reported that the university became more receptive to the annual program report and program evaluation by graduates to identify if any curriculum modifications required to accommodate changes in national and international requirements in education. Course specifications became mandatory before the start of all courses. Moreover, course evaluation survey and course reports became essential parts for application of all basic and specialized courses. Data also found that the university became more receptive to program specification, graduate evaluation by stakeholders, independent evaluation, and academic supervision. In line with our findings, previous study has also reported improvement in several aspects after the accreditation process which could enhance the quality of education (Al Mohaimeed et al., 2012). Similar findings were reported in a study done in Nigeria (Alani, 2008). 
A. E. Atia et al. - Accreditation Process and Outcomes: Experience of the University of Tripoli...

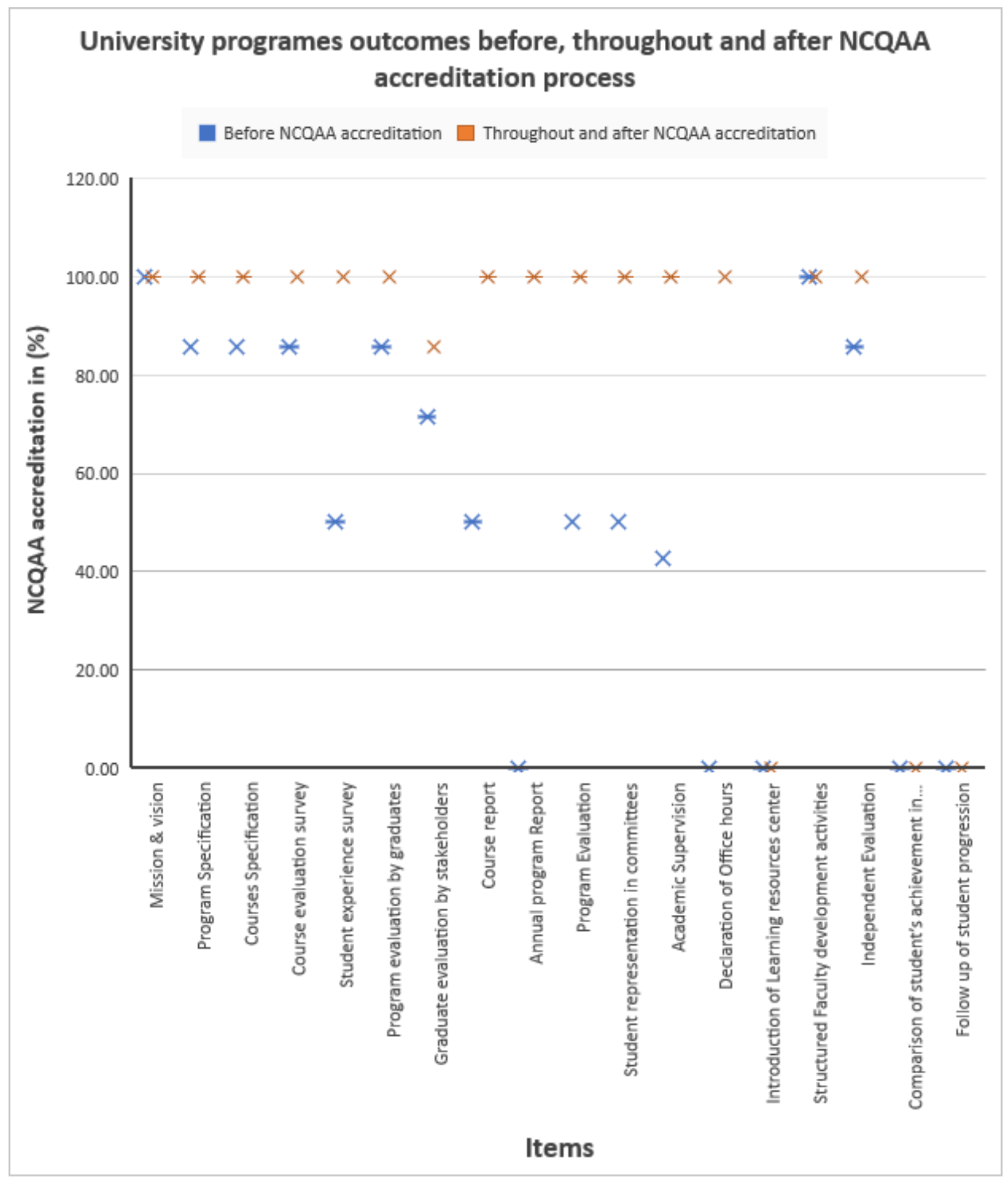

Figure 1. University programs outcomes before, throughout and after NCQAA accreditation process.

It was believed that accreditation process had a major role in stimulating student representation in committees. Moreover, the role of accreditation in improving the quality of education at the university had a very positive impact in declaration of office hours that allow students to find their instructors for consultation and advice, and consequently could positively 
impact the learning process. Student experience survey has also been improved during and after NCQAA accreditation process, representing their awareness and concerns with program evaluation. Similarly, earlier study conducted in Australia and New Zealand reported major changes to their courses in the last 10 years due to accreditation obligations. They concluded that teaching and evaluation of communication skills, student-based learning, the application of information technology in courses, and course evaluation was more consistent (Simpson, 2005). On the contrary, our results revealed insufficiency in follow up of student progression, introduction of learning resources center, and comparison of student's achievement in different courses.

Quality indicators are identified and used for all programs are presented in table 1. Programs are regularly evaluated and reported with information providing the scope to which learning results were being achieved. The records of programs evaluation show statistically significant improvement in the quality of learning from $58.3 \%$ to $83.3 \%(\mathrm{P}<0.05)$. Noticeably, departments of pharmacy and medical laboratories shows the highest improvement from $38.9 \%$ to 80.6 and 36.1 to 80.6 before and after the accreditation process, respectively $(\mathrm{P}<0.05)$.

Table1. Changes in the programs' quality of education as an impact of NCAAA accreditation process

\begin{tabular}{|c|c|c|c|}
\hline \multirow{2}{*}{ Program } & $\begin{array}{c}\text { Before } \\
\text { NCQAA } \\
\text { accreditation }\end{array}$ & $\begin{array}{c}\text { Throughout } \\
\text { and after } \\
\text { NCQAA } \\
\text { accreditation }\end{array}$ & \multirow{2}{*}{ P value } \\
\cline { 2 - 3 } & $\mathrm{N}(\%)$ & $\mathrm{N}(\%)$ & \\
\hline Management & 58.33 & 83.33 & 0.008 \\
\hline Accounting & 58.33 & 83.33 & 0.008 \\
\hline Law & 58.33 & 83.33 & 0.008 \\
\hline English & 58.33 & 83.33 & 0.008 \\
\hline Architecture & 58.33 & 83.33 & 0.008 \\
\hline Pharm. & 38.89 & 80.56 & 0.000 \\
\hline Med Lab. & 36.11 & 80.56 & 0.000 \\
\hline
\end{tabular}

Despite the applicability of the NCQAA criteria to educational institutions is controversial, our study suggests that, the impact of the accreditation processes including concentrated data collection, documentation, and analysis was clearly felt at all levels.

The role of accreditation in quality assurance and education enhancement is well documented. However, there are variances in views regarding the mechanisms by which an accreditation process impacts the quality assurance processes. Several scientists have stated that accreditation is valuable not only to assess the educational excellence of new and established institutions, but also to permit specific institutions to monitor and afford a resource that help in constant improvement of the curriculum (Simpson, 2005; Azila, \& Tan, 2005).

Owing that the accreditation and recognition is a variable procedure, the criteria and procedures of this accreditation should be repeatedly revised. This review process can be revised through feedback from observational studies, expert commentaries, institutions experiencing accreditation or recognition. Governmental strategies related to education, stakeholder consultation, and communication with other educational institutions may also be valuable. Further, regular evaluation practice against national and international accreditation criteria is worth (Bac, 2015). 
A. E. Atia et al. - Accreditation Process and Outcomes: Experience of the University of Tripoli...

\section{Conclusion}

In conclusion, our findings revealed that the process of NCQAA accreditation conducted in UTA has been positively improved the quality of education. The indicators of follow up of student progression, introduction of learning resources center, and comparison of student's achievement in different courses may give relative low implication of quality assurance in this institution, suggesting the need of more work to improve these indicators. Moreover, detailed research is advisable to test the implication of accreditation on the learning quality and improvement. Data from additional institutes would also significantly increase the relevance and rationality of the study. Nonetheless, the conclusions drawn from this study are worthy.

\section{Acknowledgements}

We acknowledge the staff of the University of Tripoli Alahlia for their support.

This research did not receive any specific grant from funding agencies in the public commercial, or not-for-profit sectors.

The authors declare no competing interests.

\section{References}

Al Mohaimeed, A., Midhet, F., Barrimah, I., \& Saleh M. N. (2012). Academic accreditation process: Experience of a medical college in Saudi Arabia. International Journal of Health Sciences (Qassim), 6(1), 23-29. http://doi.org/10.12816/0005970

Alani, R. (2008). Accreditation outcomes, quality of and access to university education in Nigeria. Quality Assurance in Education, 16(3), 301-312. http://doi.org/10.1108/09684880810886295

Atia, A., \& Elfard, S. (2020). Medical school accreditation in Libya: Current trends and future challenges. Egyptian Journal of Medical Education, 2(2), 1-4. http://doi.org/10.33328/ejme.2020.004

Azila, M., \& Tan, P. (2005). Accreditation of medical schools: The question of purpose and outcomes. Medical Journal of Malaysia, 6o(1), 35-40.

Hiyam, A. (2016). Compatibility of higher education specializations with the employment in economic activities in Saudi Arabia in the era of knowledge economy for the period 2010-2015. Journal of Business Management \& Social Sciences Research, 5(9), 36-44. http://doi.org/10.5281/zenodo.1220067

Ibrahim, H. (2004). Quality assurance and accreditation in education. Open Journal of Education, 2(2), 106-110. http://doi.org/10.12966/oje.06.06.2014

Kashisaz, S., \& Mobarak, E. (2018). The effects of private education institutes in providing modern financial knowledge in developing countries. Journal of Humanities Insights, 2(4), 172-178.

Report of the external review of British accreditation council for independent further and higher education (bac). (2015). Retrieved 15 April 2020, from https://enqa.eu/wpcontent/uploads/2015/03/BAC-Final-edit-pdf.pdf.

Simpson, I. (2005). Accreditation of medical training in Australia and New Zealand. Medical Journal of Malaysia, 6o(1), 20-23.

Tamtam, A. (2011). Higher education in Libya, system under stress. Procedia - Social and Behavioral Sciences, 29, 742-751. https://doi.org/10.1016/j.sbspro.2011.11.300 
The National Center for Quality Assurance and Accreditation in Libya (2020). Retrieved 15 April 15 2020, from https://qaa.ly/.

UNESCO European Centre for Higher Education (2007). The Rising role and relevance of private higher education in Europe. Retrieved 15 April 2020, from https://unesdoc.unesco.org/ark:/48223/pfooo0151100. 
A. E. Atia et al. - Accreditation Process and Outcomes: Experience of the University of Tripoli...

C O A $\mathrm{s}$ 